\title{
Oxygen Consumption in the Isolated Toad Retina
}

\author{
LAURA M. HAUGH-SCHEIDT ${ }^{a *}$, ROBERT A. LINSENMEIER ${ }^{\mathrm{a}, \mathrm{b}} \dagger$ AND EDWIN R. GRIFF \\ Departments of a Biomedical Engineering and ${ }^{\mathrm{b}}$ Neurobiology and Physiology, Northwestern University, \\ Evanston, IL 60208, U.S.A. and ' Department of Biological Sciences, University of Cincinnati, \\ Cincinnati, $\mathrm{OH}$ 45221, U.S.A.
}

(Received Houston 15 August 1995 and accepted in revised form 28 February 1995)

\begin{abstract}
Retinal $\mathrm{O}_{2}$ utilization was studied to identify the $\mathrm{O}_{2}$ consuming processes in the retina and the spatial distribution of those processes. Neural retina, retinal pigment epithelium and choroid were dissected from the toad eye and superfused with an oxygenated Ringer's solution. Double-barreled microelectrodes were used to measure $\mathrm{O}_{2}$ and local voltage simultaneously within the retina in both light and dark adaptation. The profile of $\mathrm{PO}_{2}$ was measured during a withdrawal of the electrode tip across the retinal pigment epithelium and through the neural retina. The $\mathrm{PO}_{2}$ decreased through the distal retina, reaching a minimum in the inner segment or outer nuclear layer, and then increased steadily through the proximal retina. From fitting $\mathrm{PO}_{2}$ profiles measured in the dark-adapted retina to a three-layer diffusion model, $\mathrm{O}_{2}$ consumption was found to be $1 \cdot 0 \pm 0.4$ and $0 \cdot 4 \pm 0 \cdot 3 \mathrm{ml} \mathrm{O}_{2}(100 \mathrm{~g} \mathrm{~min})^{-1}$ in the outer and inner halves of the retina, respectively. Light decreased consumption in both halves of the retina. In steady illumination $\left(500 \mathrm{~nm}\right.$ ) that saturated the ERG b- and c-waves, $\mathrm{O}_{2}$ utilization decreased significantly to $48 \%$ and $68 \%$ of the dark values in the outer and inner retina, respectively. When $\mathrm{Na}^{+}$was removed from the superfusate to inhibit the photoreceptor $\mathrm{Na}^{+} / \mathrm{K}^{+}$pump, $\mathrm{O}_{2}$ consumption in the outer retina decreased by about the same amount as in light, but $\mathrm{O}_{2}$ consumption in the inner retina was not significantly affected.

(C) 1995 Academic Press Limited

Key words: retina; oxygen; oxygen metabolism; dark adaptation; light adaptation.
\end{abstract}

\section{Introduction}

Studies of the rate of oxygen consumption $\left(\mathrm{QO}_{2}\right)$ of the retina have shown that oxygen demand decreases in light, as compared to dark, in the retina of frog (Sickel, 1972; Kimble, Svoboda and Ostroy, 1980; Zuckerman and Weiter, 1980), cat (e.g. Linsenmeier, 1986), monkey (Stefansson, Wolbarsht and Landers, 1983; Ahmed et al., 1993), rabbit (Ames et al., 1992) and rat (Medrano and Fox, 1993). By employing measurements of intraretinal oxygen tension $\left(\mathrm{PO}_{2}\right)$ in the cat, the values of $\mathrm{QO}_{2}$ for the photoreceptors were derived from a diffusion model of the outer retina (Linsenmeier, 1986; Haugh, Linsenmeier and Goldstick, 1990). High oxygen consumption was localized to the photoreceptor inner segments (Haugh et al., 1990) where mitochondria are located (Sjostrand, 1953; Robertis, 1956: Cohen and Noell, 1965).

A major component of light-evoked changes in photoreceptor $\mathrm{QO}_{2}$ is a light-dependent change in the rate of sodium pumping (Kimble et al., 1980; Zuckerman and Weiter, 1980; Shimazaki and Oakley, 1984), but other possible mechanisms have not been thoroughly investigated. Furthermore, there is a paucity of information on $\mathrm{QO}_{2}$ in the inner retina,

\footnotetext{
* Present address: Department of Ophthalmology and Visual Sciences, University of Illinois College of Medicine, 1855 West Taylor Street, Chicago, IL 60612, U.S.A.

† For correspondence at: Department of Biomedical Engineering Northwestern University, 2145 Sheridan Road, Evanston, IL 60208-3107, U.S.A.
}

because the retinal circulation has made it impossible, until recently (Braun, Linsenmeier and Goldstick, 1995), to model that part of the retina in cat or monkey.

The present work was undertaken in order to fill some of the gaps in our understanding of retinal oxygen utilization, and had several specific goals. First, while the change in $\mathrm{QO}_{2}$ with light has been convincingly demonstrated in all species, the spatial localization has not been determined satisfactorily in the submammalian vertebrate retina, the structure of which is somewhat different than the mammalian retina. Consequently, retinal oxygen profiles (in the steady state) were measured in the isolated toad retina and used to develop an appropriate mathematical model of oxygen diffusion and consumption for this species. Second, the mathematical modelling was extended to the inner retina, and values of $\mathrm{QO}_{2}$ were obtained for both inner and outer retina in both light and dark adaptation. The conclusions from these experiments depend strongly on the development of a model. Third, the mechanisms of light-dependent changes in photoreceptor oxygen consumption were studied.

Questions concerning the mechanisms of photoreceptor $\mathrm{QO}_{2}$ could be addressed by positioning an electrode at one location in the retina and recording transient responses to illumination. These experiments. which did not rely on the diffusion modelling, are reported in the accompanyimg paper (HaughScheidt, Griff and Linsenmeier, 19195). Ion substitu- 
tions and pharmacological manipulations were necessary to examine mechanisms of $\mathrm{QO}_{2}$ changes, so an isolated retina was used in both of these studies. The toad retina was chosen because a wealth of information is available on its mechanisms of phototransduction and light and dark adaptation, because it maintains a stable light response for hours in vitro, and because photoreceptor recordings, which may be necessary in continued studies, are feasible in this species.

\section{Materials and Methods}

\section{Preparation of Isolated Retina-RPE-Choroid}

Toads (Bufo marinus) were obtained from Delta Biologicals (Tucson, AR, U.S.A.), maintained on a 12-hr light/dark schedule, and fed a diet of crickets. Light-adapted toads were sedated in ice, double pithed, and the eyes were enucleated. Dissection of the neural retina, retinal pigment epithelium (RPE) and choroid was performed in a dish filled with a Hepes-buffered Ringer's solution, bubbled with $100 \% \mathrm{O}_{2}$. The tissue was placed in a chamber that has been previously described (Miller and Steinberg, 1977), and superfused on both sides (2-3 $\mathrm{ml} \mathrm{min}^{-1}$ ) with a Ringer's solution. The normal Ringer's solution contained $\mathrm{NaCl}$ (110 mM), $\mathrm{KCl}(2 \mathrm{~mm}), \mathrm{CaCl}_{2}(1.8 \mathrm{~mm}), \mathrm{MgCl}_{2}$ (1 mM), glucose (10 mM) and Hepes (N-2-hydroxyethylpiperazine- $\mathrm{N}^{\prime}$-2-ethanesulphonic acid) (10 mM), adjusted to $\mathrm{pH} 7 \cdot 8$ with $\mathrm{NaOH}$. For low $\left[\mathrm{Na}^{+}\right]$solutions, $\mathrm{Na}^{+}$was replaced with $\mathrm{N}$-methyl-D-glucamine, which is not expected to pass through the light-sensitive channels or support $\mathrm{Na}^{+} / \mathrm{Ca}^{2+}$ exchange. Inhibiting the $\mathrm{Na}^{+} / \mathrm{Ca}^{2+}$ transporter is known to elevate intracellular $\left[\mathrm{Ca}^{2+}\right]$ in photoreceptors (Yau and Nakatani, 1984, 1985: Miller and Korenbrot, 1987); thus under low $\left[\mathrm{Na}^{+}\right]$conditions, the $\left[\mathrm{Ca}^{2+}\right]$ was lowered by adding $2.0 \mathrm{~mm}$ EGTA [ethylene glycol bis ( $\beta$-aminoethyl ether)-N,N, $\mathrm{N}^{\prime}, \mathrm{N}^{\prime}$-tetra-acetic acid]. The calculated free $\left[\mathrm{Ca}^{2+}\right]$ was about $60 \mathrm{~nm}$ (Goldstein, 1979). The $\left[\mathrm{Ca}^{2+}\right]$ in the subretinal space was probably somewhat higher, but within the physiological range for intracellular $\left[\mathrm{Ca}^{2+}\right]$ in photoreceptors (Ratto et al., 1988; Korenbrot and Miller, 1989). The superfusing solution was bubbled with $100 \% \mathrm{O}_{2}$ in a reservoir that was gravity fed into the open chamber, where the $\mathrm{PO}_{2}$ was about $400 \mathrm{mmHg}$. There was a $\mathrm{PO}_{2}$ gradient through a stagnant layer of fluid adjacent to the retina so the $\mathrm{PO}_{2}$ at the retinal surfaces was less than $400 \mathrm{mmHg}$. Electrical contact was made with each bath via a pair of agar-saline bridges, which were connected to calomel $\left(\mathrm{Hg} / \mathrm{Hg}_{2} \mathrm{Cl}_{2}\right)$ electrodes. Diffuse light, after passing through condensing lenses and an interference filter $(500 \pm 10 \mathrm{~nm})$, was directed at the tissue from above by a front-surface mirror. The unattenuated illumination at $500 \mathrm{~nm}$ was about $8 \times 10^{14}$ quanta $\left(\mathrm{cm}^{2} \mathrm{sec}\right)^{-1}$. Neutral density filters were added for dimmer illumination. Experiments were performed at room temperature, approximately $22^{\circ} \mathrm{C}$.

\section{Microelectrodes and Recording}

Intraretinal measurements were made with doublebarreled microelectrodes that have been described previously by Linsenmeier and Yancey (1987) except that each barrel of the glass used to constuct the electrodes was $1 \mathrm{~mm}$ in diameter. The oxygen cathode diameter was about $1 \mu \mathrm{m}$, and the total tip diameter of the microelectrode was about $5 \mu \mathrm{m}$. The ratio of recess depth to cathode diameter was greater than 5 so that the electrodes were insensitive to the diffusion properties of the medium and so that they disturbed the

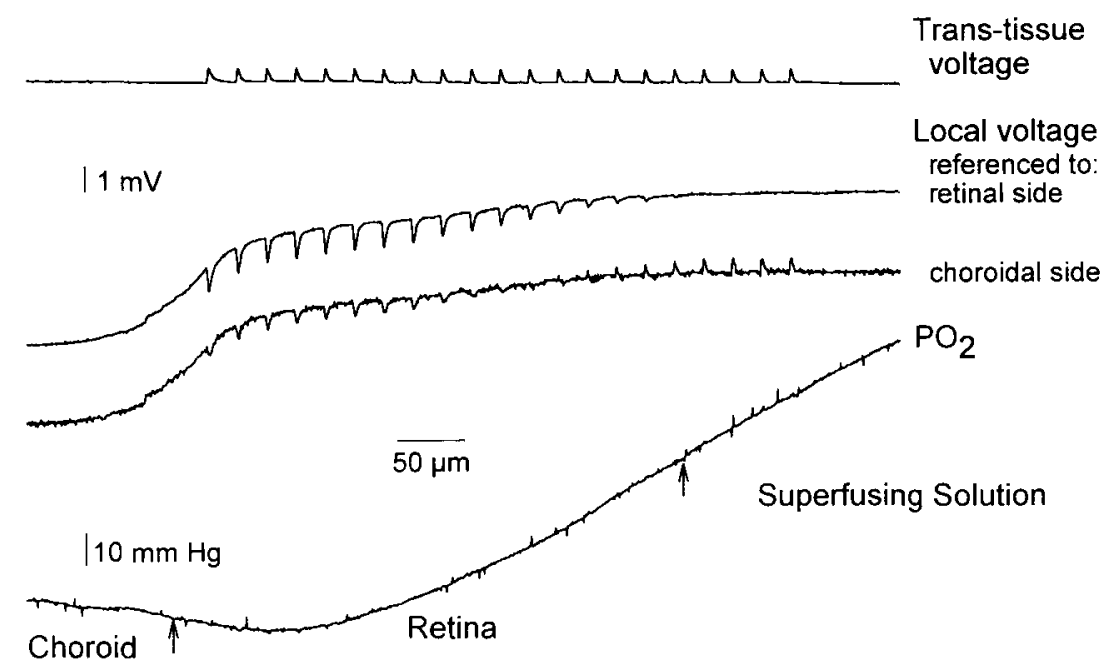

FIG. 1. Microelectrode recordings (local voltage and $\mathrm{PO}_{2}$ ) from a withdrawal of the electrode, and the trans-tissue voltage. There was an increase in local voltage as the microelectrode moved across the RPE. This voltage change was used to determine the beginning of the retinal profile (arrow). The local ERG was recorded in responses to dim flashes of illumination $(0 \cdot 1$-sec flash every $10 \mathrm{sec}$ ) to determine the end of the retinal profile (arrow). There was a $\mathrm{PO}_{2}$ gradient in unstirred layers on either side of the retina. (Data: 60DAP02). 
tissue $\mathrm{PO}_{2}$. minimally (Schneiderman and Goldstick 1978). The $\mathrm{O}_{2}$ electrodes were calibrated by bubbling gases containing $10 \%, 21 \%$ and $49 \%$ (or $100 \%$ ) $\mathrm{O}_{2}$ in saline or Ringer's solution. After an experiment, the calibration was repeated for at least two $\mathrm{O}_{2}$ concentrations. The final calibration slope was within $10 \%$ of the initial calibration and an average of the two was used for the analysis. The mean calibration slope was $12.5 \mathrm{mmHg} \mathrm{pA}^{-1}$ and the current at zero $\mathrm{mmHg}$, extrapolated from the calibration, was less than $5 \%$ of the air current. The current from the $\mathrm{O}_{2}$ electrode was recorded with a picoammeter (model 614, Keithley Instruments, Cleveland, OH, U.S.A.). The voltage barrel was referenced to both the choroidal bath and the retinal bath in order to measure the trans-epithelial and the trans-retinal potentials, respectively; details of the recording configuration have been described previously (Griff, 1990).

\section{Measurement of Retinal $\mathrm{PO}_{2}$ Profiles}

The microelectrode was advanced with a hydraulic microdrive (Model 600, David Kopf Instruments, Tujunga, CA, U.S.A.) through the bath on the retinal side, and then through the retina in steps. The intraretinal voltage response to brief flashes of dim light, the local electroretinogram (ERG), was observed while penetrating the retina to ensure that the electrode was moving through and not pushing on the retina. A voltage drop, the trans-epithelial potential, measured by the microelectrode indicated that the electrode had penetrated through the RPE. Figure 1 shows the recordings of oxygen and voltage during a withdrawal of the electrode $\left(2 \mu \mathrm{m} \mathrm{sec}^{-1}\right)$ from the choroid to the bath on the retinal side. There was an increase in the DC potential during the withdrawal which indicated that the electrode had passed across the RPE. Midway through this voltage change was considered the beginning of the retinal profile $(x=0)$, and the retinal response to a brief flash of light was used to identify the end of the retinal profile (marked with arrows in Fig. 1). The scale bar has been corrected for the angle of penetration $\left(65^{\circ}\right.$ from the retinal surface) as have the lengths of all the retinal $\mathrm{PO}_{2}$ profiles in this study.

Retinal $\mathrm{PO}_{2}$ profiles (three to five profiles) were first measured after the retina had dark-adapted for at least $30 \mathrm{~min}$ and before any other manipulation. Then, a manipulation was made that was expected to affect retinal $\mathrm{QO}_{2}$ (such as illumination or a solution change) while the $\mathrm{PO}_{2}$ change in the outer retina was recorded. When the retinal $\mathrm{PO}_{2}$ had stabilized, the electrode was advanced through the RPE, and then the $\mathrm{PO}_{2}$ profile was recorded as before. Retinal $\mathrm{PO}_{2}$ profiles were recorded in a normal $\left[\mathrm{Na}^{+}\right]$solution and in a low $\left[\mathrm{Na}^{+}\right]$-low $\left[\mathrm{Ca}^{2+}\right]$ solution, in both dark- and lightadapted conditions. There was no voltage response to dim flashes of light under light-adapted conditions nor when the retina was in lowered $\mathrm{Na}^{+}$. Therefore, the beginning of the retinal profile was determined as before, but the total retinal thickness was determined from the control profiles (i.e. normal $\left[\mathrm{Na}^{+}\right]$, dark conditions) in the same retina. A diffusion model of intraretinal $\mathrm{O}_{2}$ distribution and consumption was fitted to each of the $\mathrm{PO}_{2}$ profiles. Repeated measurements from the same retina were averaged; then the mean values and standard deviations were calculated for all retinas. All statistical comparisons were evaluated using a $t$-test and were considered significant for $P<0 \cdot 05$.

\section{Oxygen Diffusion Model}

A simple diffusion model was developed that fitted the retinal $\mathrm{PO}_{2}$ data with little error. The retina was modelled as a slab of tissue with diffusion occurring only perpendicular to the retinal surface. The model consisted of a fixed number of layers that each had a constant $\mathrm{QO}_{2}$, but the boundaries between layers and the $\mathrm{O}_{2}$ consumption within a retinal layer were adjustable parameters. By fitting diffusion models with different numbers of layers to the $\mathrm{PO}_{2}$ data, three layers were found to be the fewest that would adequately fit retinal $\mathrm{PO}_{2}$ profiles (for discussion see Haugh, 1992). Furthermore, the $O_{2}$ consumption $\left(Q_{1}\right)$ in the layer closest to the choroid could be taken to be zero (Haugh, 1992; Haugh, Linsenmeier and Griff, 1992), as expected due to the absence of mitochondria in the photoreceptor outer segment layer. The steadystate diffusion equation is:

$$
D k \frac{d^{2} P}{d x^{2}}=Q
$$

The diffusion coefficient $(D)$ and solubility $(k)$ have been assumed to be constant through the retina. Measurements of $\mathrm{O}_{2}$ diffusion in cat retina have indicated that $D$ in the retina is about $70 \%$ of $D$ in saline (Roh, Goldstick and Linsenmeier, 1990) which gave a value of $1.5 \times 10^{-5} \mathrm{~cm}^{2} \mathrm{sec}^{-1}$ (at $25^{\circ} \mathrm{C}$ ). The solubility of $\mathrm{O}_{2}$ has not been measured in retina so the value in plasma (at $25^{\circ} \mathrm{C}$ ), $3.3 \times 10^{-5} \mathrm{ml} \mathrm{O}_{2}(\mathrm{ml}$ tissue $\mathrm{mmHg}^{-1}$, was used (e.g. Goldstick, 1973). The solution of the diffusion equation for a general threelayer model has been given previously (Haugh et al., 1990). While that model is identical in form to the one applied here, it should be noted that the model for cat required three layers for the outer half of the retina, while the model for toad required only three layers for the entire retina. In the present model, $L$ was the thickness of the whole retina and was determined by the length of the electrode withdrawal (Fig. 1). The parameters of the toad diffusion model are illustrated schematically in Fig. 2, where $P_{\mathrm{C}}$ and $P_{\mathrm{L}}$ are the $\mathrm{PO}_{2}$ at the choroid/retina boundary and at the innermost retinal surface, respectively, $L_{1}$ and $L_{2}$ are the boundaries between layers, and $Q_{1}, Q_{2}$ and $Q_{3}$ are the $\mathrm{QO}_{2}$ within each layer. The diffusion model was fitted 


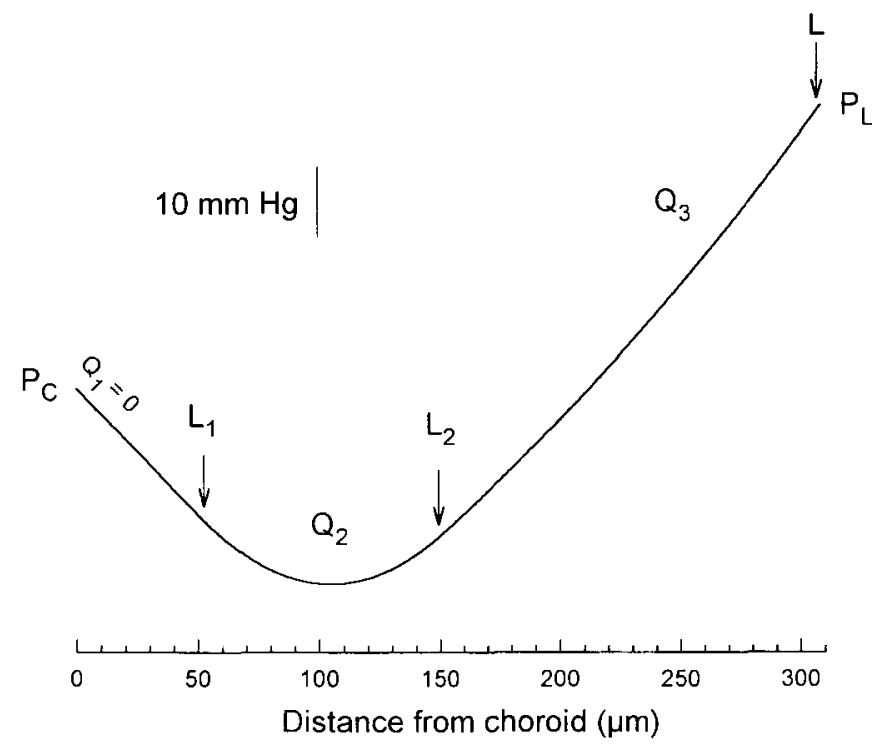

FIG. 2. The parameters for the three-layer diffusion model. The model of retinal $\mathrm{PO}_{2}$ is plotted as a function of distance from the choroid. The retinal thickness, $L$, was determined from the length of the microelectrode withdrawals, and corrected for the penetration angle. The $\mathrm{PO}_{2}$ at the retina/choroid border and at the retina/vitreous border are $P_{\mathrm{C}}$ and $P_{\mathrm{L}}$, respectively. Other adjustable parameters in the three-layer diffusion model are $L_{1}$ and $L_{2}$, the boundaries between layers, and $Q_{1}, Q_{2}, Q_{3}$, the $Q O_{2}$ within each layer. Parameter values used to generate the sample $\mathrm{PO}_{2}$ profile were similar to those that fit retinal $\mathrm{PO}_{2}$ profiles, i.e. $Q_{1}=0$ and $Q_{2}>Q_{3}$.

to retinal $\mathrm{PO}_{2}$ profiles using a nonlinear least-squares regression routine that employed Marquardt's method (Press et al., 1989). A computer program was developed that adjusted the parameter values and found the combination that minimized the sum of the squared error. The boundaries between layers of consumption in the model were not constrained by the cell layers in the retina.

A $95 \%$ confidence interval for each parameter of the model was calculated for each fit to the $\mathrm{PO}_{2}$ data. For $P_{\mathrm{C}}$ and $P_{\mathrm{L}}$, the confidence interval was never greater than $\pm 0.5 \mathrm{mmHg}$. For $L_{1}$ and $L_{2}$, the confidence interval was typically less than $\pm 10 \mu \mathrm{m}$. The size of the confidence intervals for $Q_{2}$ and $Q_{3}$ was usually $\pm 0 \cdot 1$ to $\pm 0 \cdot 5$ times the optimum values (a few intervals were even larger). The value for $Q$ within each layer, therefore, was not as well constrained as the values for $P_{\mathrm{C}}, P_{\mathrm{L}}, L_{1}$ and $L_{2}$. Furthermore, the correlation coefficient between $Q_{2}$ and either $L_{1}$ or $L_{2}$ within each fit was often between 0.90 and 0.95 , implying that different combinations of these parameters could give similar fits. As $Q_{2}$ increased from the optimum value, a reasonable fit could be obtained by decreasing $L_{2}-L_{1}$. Because of this inverse variation, measures of retinal $\mathrm{QO}_{2}$ that utilized the product of values of $Q$ and $L$ were more closely constrained. One of these measures is the weighted average $\mathrm{QO}_{2}$ of the entire retina:

$$
Q_{\text {entire }}=\left(Q_{1} L_{1}+Q_{2}\left(L_{2}-L_{1}\right)+Q_{3}\left(L-L_{2}\right)\right) \frac{1}{L}
$$

The value for $Q_{\text {entire }}$ changed very little when calculated from parameters that gave comparable fits. Similar results were found when fitting a diffusion model to retinal $\mathrm{PO}_{2}$ profiles in cat (Haugh et al., 1990). In this paper both the fitted parameters and the weighted consumption values are given.

\section{Results}

\section{Dark Adaptation}

Profiles of the $\mathrm{PO}_{2}$ as a function of retinal depth were measured in 64 dark-adapted retinas (45 toads; 189 profiles). Two dark-adapted $\mathrm{PO}_{2}$ profiles that were recorded sequentially from the same retina are shown in Fig. 3 (top), along with the diffusion model (smooth curve) fitted to those data. In Fig. 3 and in subsequent figures, profiles are offset vertically so that each can be seen clearly. The $\mathrm{PO}_{2}$ at the choroid/retina boundary $\left(P_{\mathrm{C}}\right)$ was typically lower than at the vitreous/retina boundary $\left(P_{\mathrm{L}}\right)$. These values were both lower than the $\mathrm{PO}_{2}$ in the bulk solution due to the presence of unstirred layers on both sides of the retina, through which oxygen had to diffuse. The unstirred layer on the vitreal side consisted of vitreous humor that adhered to the retina, and on the choroidal side was the choroid itself, which was presumably somewhat thicker, accounting for the lower $\mathrm{PO}_{2}$ at that side of the retina. Profiles recorded in the dark-adapted retina had a minimum $\mathrm{PO}_{2}$ between the two boundaries, indicating that oxygen was supplied from both sides to the highly consuming middle layer of the tissue. The minimum $\mathrm{PO}_{2}$ was always well above zero.

The three-layer diffusion model fitted retinal $\mathrm{PO}_{2}$ data with little error, about $1 \cdot 1 \mathrm{mmHg}$ (root-meansquared error) for each fit. Repeated measurements were averaged to give a set of parameters that represented each retina. The mean parameter values 


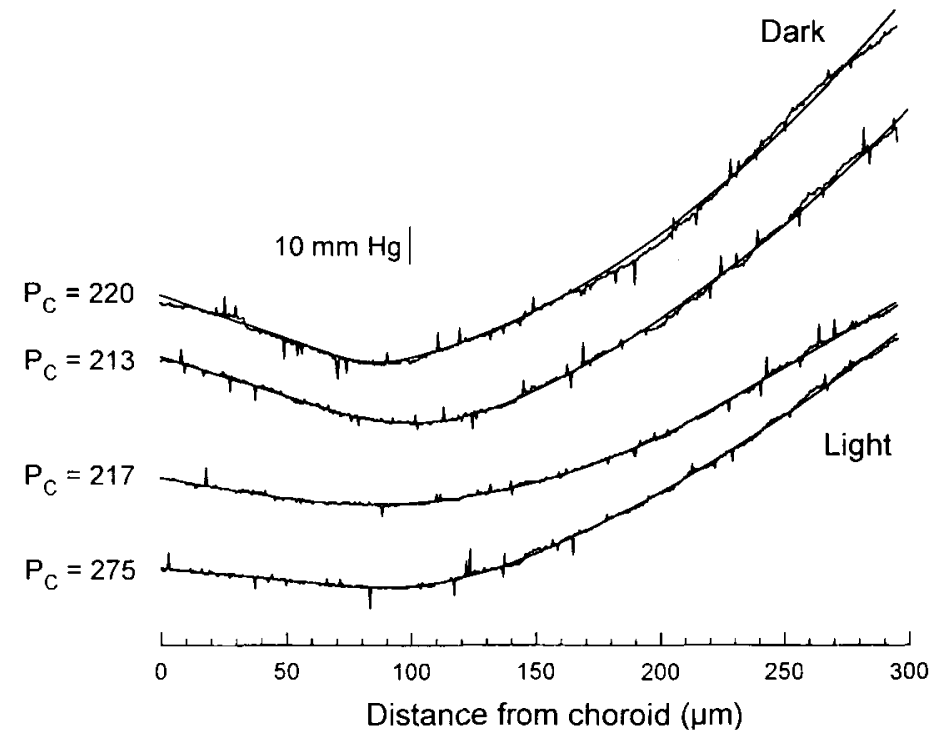

FIG. 3. Retinal $\mathrm{PO}_{2}$ profiles measured in dark-adapted and in light-adapted conditions. The profiles, and the diffusion model fitted to each, are vertically offset for clarity. Two $\mathrm{PO}_{2}$ profiles that were measured in a dark-adapted retina are shown at the top. The light was turned on and the retina was allowed to adapt during which time retinal $\mathrm{PO}_{2}$ increased (not shown). Two retinal profiles that were measured in the light-adapted condition are shown at the bottom. The model parameters were used

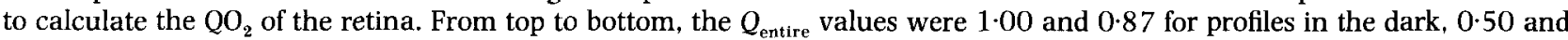
0.59 for profiles in the light. $\mathrm{QO}_{2}$ values are in $\mathrm{ml} \mathrm{O}_{2}\left(100 \mathrm{~g} \mathrm{~min}^{-1}\right.$. (Data: 57DAP08, 09, 57LAP05, 04).

TABLE I

Parameter values (mean \pm s.D.) from the diffusion model fitted to retinal $\mathrm{PO}_{2}$ profiles. $(n=$ number of retinas)

\begin{tabular}{|c|c|c|c|c|c|c|c|c|c|}
\hline Conditions & $n$ & $P_{\mathrm{C}}$ & $P_{\mathrm{L}}$ & $L_{1}$ & $L_{2}$ & $L$ & $Q_{1}$ & $Q_{2}$ & $Q_{3}$ \\
\hline $\begin{array}{l}\text { Dark } \\
\quad \text { Normal }\left[\mathrm{Na}^{+}\right]\end{array}$ & 64 & $154 \pm 56$ & $198 \pm 70$ & $52 \pm 17$ & $150 \pm 34$ & $310 \pm 20$ & 0 & $1 \cdot 88 \pm 0 \cdot 83^{*}$ & ${ }^{k} 0 \cdot 30 \pm 0 \cdot 24$ \\
\hline $\begin{array}{l}\text { Light } \\
\quad \text { Normal }\left[\mathrm{Na}^{+}\right]\end{array}$ & 25 & $164 \pm 77$ & $190 \pm 84$ & $63 \pm 28$ & $138 \pm 42$ & $309 \pm 15$ & 0 & $1 \cdot 21 \pm 0 \cdot 92$ & $0 \cdot 25 \pm 0 \cdot 28$ \\
\hline $\begin{array}{l}\text { Dark } \\
\quad \text { Low }\left[\mathrm{Na}^{+}\right]\end{array}$ & 13 & $262 \pm 75$ & $281 \pm 81$ & $51 \pm 17$ & $164 \pm 43$ & $300 \pm 20$ & 0 & $1 \cdot 06 \pm 0.44$ & $0 \cdot 29 \pm 0 \cdot 19$ \\
\hline $\begin{array}{l}\text { Light } \\
\quad \text { Low }\left[\mathrm{Na}^{+}\right]\end{array}$ & 7 & $281 \pm 86$ & $318 \pm 90$ & $51 \pm 16$ & $188 \pm 50$ & $308 \pm 23$ & 0 & $0.94 \pm 0.38$ & $0 \cdot 22 \pm 018$ \\
\hline
\end{tabular}

The units of $P, L$ and $Q$ are: $\mathrm{mmHg}, \mu \mathrm{m}$ and $\mathrm{ml} \mathrm{O}_{2}(100 \mathrm{~g} \mathrm{~min})^{-1}$, respectively.

* Indicates a value that is significantly different from each other value in the column $(P<0.05)$.

for all the retinas are given in Table I. Layer 1 coincided with the location of the photoreceptor outer segments. Photoreceptor inner segments were located within layer 2 , which occupied about $30 \%$ of the retina and had the highest $\mathrm{QO}_{2}$, about six times the $\mathrm{QO}_{2}$ of layer 3, which occupied the inner half of the retina.

\section{Light Adaptation}

To study the effect of light on retinal $\mathrm{QO}_{2}$, the retina was light-adapted with steady illumination that saturated the b- and c-waves of the ERG. In response to the adapting light, intraretinal $\mathrm{PO}_{2}$ increased. After the $\mathrm{PO}_{2}$ reached a steady state during illumination. retinal $\mathrm{PO}_{2}$ profiles were measured. Retinal $\mathrm{PO}_{2}$ profiles were measured in light adaptation from 25 retinas ( 16 toads; 70 profiles) and were fitted to the same diffusion model as were the data from dark-adapted retinas. Plotted in Fig. 3 (bottom) are two $\mathrm{PO}_{2}$ profiles from the same light-adapted retina. As was found when modelling profiles from dark-adapted retinas, the $\mathrm{QO}_{2}$ in layer 2 was larger than in the other layers (Table I). Furthermore, $Q_{2}$ was significantly lower in light than in dark. When two profiles from light-adapted retinas with outlying $Q_{3}$ values (more than 2 s.D. greater than the mean) were omitted, $Q_{3}=0 \cdot 17 \pm 0 \cdot 16(n=23) \mathrm{ml}$ $\mathrm{O}_{2}(100 \mathrm{~g} \mathrm{~min})^{-1}$, and a significant light-induced reduction in $Q_{3}$ was revealed. No other parameters were significantly different from the values in the darkadapted retina. A second episode of light adaptation repeated after the retina had returned to the darkadapted condition, gave similar results $(n=2)$. 


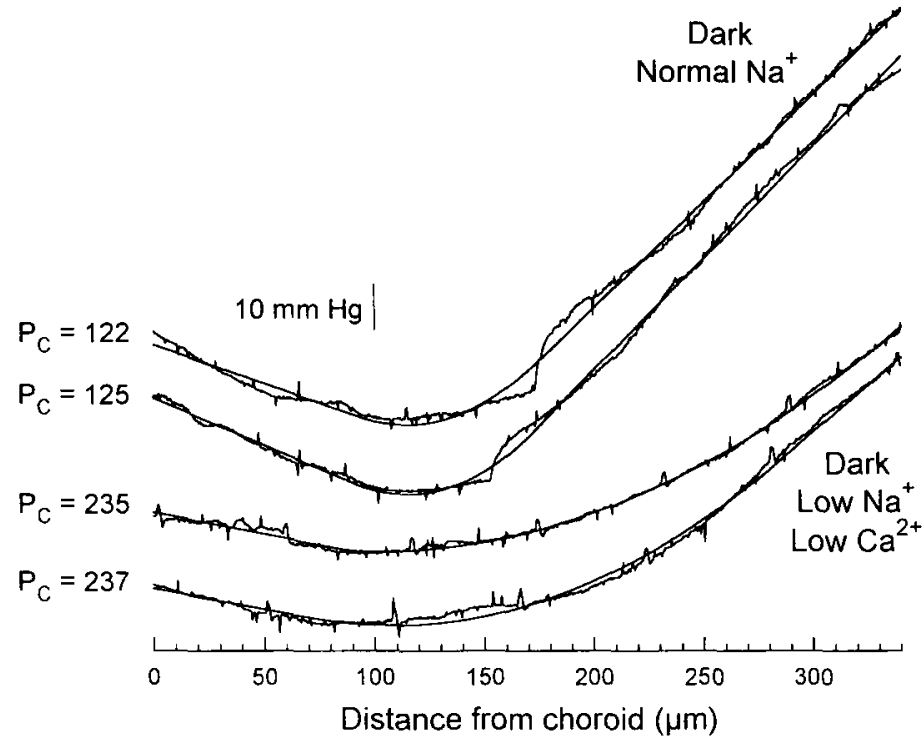

Fig. 4. Retinal $\mathrm{PO}_{2}$ profiles measured in normal $\left[\mathrm{Na}^{+}\right]$and in low $\left[\mathrm{Na}^{+}\right]$conditions. Two $\mathrm{PO}_{2}$ profiles that were measured in a dark-adapted retina are shown at the top. The superfusate was switched to a low $\left[\mathrm{Na}^{+}\right]-$low $\left[\mathrm{Ca}^{2+}\right]$ solution which led to an increase in retinal $\mathrm{PO}_{2}$ (not shown). Two retinal profiles that were subsequently measured are shown at the bottom. The model parameters were used to calculate the $\mathrm{QO}_{2}$ of the retina. From top to bottom, the $Q_{\text {entire }}$ values were 0.56 and 0.60 for profiles in normal $\left[\mathrm{Na}^{+}\right], 0 \cdot 44$ and $0 \cdot 43$ for profiles in low $\left[\mathrm{Na}^{+}\right] . \mathrm{QO}_{2}$ values are in units of $\mathrm{ml} \mathrm{O}_{2}(100 \mathrm{~g} \mathrm{~min})^{-1}$. (Data: 67DAPO2, 03, 06, 07).

\section{Lowered Extracellular $\left[\mathrm{Na}^{+}\right]$}

Retinal $\mathrm{PO}_{2}$ profiles were also recorded under conditions that were expected to inhibit $\mathrm{Na}^{+} / \mathrm{K}^{+}$ pumping. The $\mathrm{PO}_{2}$ profiles were first measured in the dark-adapted retina, and then the superfusing solution was replaced with a low $\left[\mathrm{Na}^{+}\right]$-low $\left[\mathrm{Ca}^{2+}\right.$ solution. Removing $\mathrm{Na}^{+}$led to an increase in retinal $\mathrm{PO}_{2}$, often greater than the light-evoked increase. Retinal $\mathrm{PO}_{2}$ profiles were measured under the dark-adapted, low [ $\left.\mathrm{Na}^{+}\right]$conditions in 13 retinas (ten toads; 50 profiles). In Fig. 4, $\mathrm{PO}_{2}$ profiles from a dark-adapted retina are plotted, along with the diffusion model fitted to each. The two profiles at the top were measured before $\mathrm{Na}^{+}$ removal and the bottom two profiles were measured after the retina was exposed to low extracellular $\left[\mathrm{Na}^{+}\right]$ for $120 \mathrm{~min}$ and $140 \mathrm{~min}$, respectively. The shape of the profile in low $\left[\mathrm{Na}^{+}\right]$was much flatter than the profile in normal $\left[\mathrm{Na}^{+}\right]$. The $\mathrm{PO}_{2}$ was elevated throughout the retina, resulting in a significant increase in $P_{\mathrm{C}}$ and $P_{\mathrm{L}}$ when compared to the normal $\left[\mathrm{Na}^{+}\right]$conditions (Table I). The boundaries between layers were not different from the parameters values estimated under the other conditions. However, lowering $\left[\mathrm{Na}^{+}\right]$in the dark-adapted retina resulted in a significant decrease in $Q_{2}$.

The effect of low $\left[\mathrm{Na}^{+}\right]$on $\mathrm{PO}_{2}$ was also examined in light-adapted retinas, using the same level of illumination that was used for light adaptation in normal $\left[\mathrm{Na}^{+}\right]$solution. When the retina was in low $\left[\mathrm{Na}^{+}\right]$, a light-evoked decrease in retinal $\mathrm{PO}_{2}$ was measured in the outer retina (Haugh-Scheidt et al., 1995); however, the magnitude of the change was smaller than the light-evoked increase in $\mathrm{PO}_{2}$ in normal $\left[\mathrm{Na}^{+}\right]$. In low $\left[\mathrm{Na}^{+}\right]$, the $\mathrm{PO}_{2}$ profiles measured in light adaptation were not noticeably different from the profiles measured in dark adaptation, and the parameter values were not significantly different.

\section{Oxygen Consumption in the Inner and Outer Retina}

For comparison of the $\mathrm{QO}_{2}$ values found from modelling in this study with whole-retina $\mathrm{QO}_{2}$ measurements from other studies, it was necessary to calculate the weighted average $\mathrm{QO}_{2}\left(Q_{\text {entire }}\right)$ using several of the model parameters (see Methods). Likewise, for comparison of the $\mathrm{QO}_{2}$ of the outer and inner retina, the weighted average $\mathrm{QO}_{2}$ for the outer $50 \%$ of the retina (photoreceptors), $Q_{\mathrm{OR}}$, can be compared with a similarly derived measure of consumption of the inner $50 \%$ of the retina, $Q_{\mathrm{IR}}$. These parameters combine values of $Q$ and $L$, so they are less sensitive to slight fitting errors than the model parameters themselves (see Methods). The average $\mathrm{QO}_{2}$ of the outer half of the retina was given by

$$
Q_{\mathrm{OR}}=\left(Q_{2}\left(L_{2}-L_{1}\right)+Q_{3}\left(\frac{L}{2}-L_{2}\right)\right) \frac{1}{L / 2} \text { if } L_{2}<\frac{L}{2}
$$

if layer three was partially in the outer retina. The $Q_{2}$ term was the major determinant of $Q_{\mathrm{OR}}$, not only because it was larger than $Q_{3}$, but also because $L / 2-L_{2}$ was usually small. In cases where layer two extended into the inner half of the retina, $\mathrm{QO}_{2}$ of the outer retina was given by

$$
Q_{\mathrm{OR}}=Q_{2}\left(\frac{L}{2}-L_{1}\right) \frac{1}{L / 2} \quad \text { if } L_{2}>\frac{L}{2}
$$

The value of $Q_{O R}$ was the rate of $\mathrm{O}_{2}$ consumption that would be measured if only the outer $50 \%$ of the retina 


\section{TABLE II}

Retinal $\mathrm{QO}_{2}$ (mean \pm s.D.) calculated from parameter values of the diffusion model fitted to retinal $\mathrm{PO}_{2}$ profiles. ( $n=$ number of retinas)

\begin{tabular}{|c|c|c|c|}
\hline Conditions & $n Q_{\text {entire }}$ & $Q_{\mathrm{OR}}$ & $Q_{\text {IR }}$ \\
\hline $\begin{array}{l}\text { Dark } \\
\quad \text { Normal }\left[\mathrm{Na}^{+}\right]\end{array}$ & $640 \cdot 71 \pm 0 \cdot 30^{\prime}$ & ${ }^{*} 0.99 \pm 0.41^{*}$ & ${ }^{*} 0.44 \pm 0.31$ \\
\hline $\begin{array}{l}\text { Light } \\
\quad \text { Normal }\left[\mathrm{Na}^{+}\right]\end{array}$ & $250 \cdot 39 \pm 0 \cdot 27$ & $0 \cdot 48 \pm 0 \cdot 34$ & $0.30 \pm 0.25 \dagger$ \\
\hline $\begin{array}{l}\text { Dark } \\
\text { Low }\left[\mathrm{Na}^{+}\right]\end{array}$ & $130 \cdot 47 \pm 0 \cdot 21$ & $0.50 \pm 0.23$ & $0.43 \pm 0.22$ \\
\hline $\begin{array}{l}\text { Light } \\
\text { Low }\left[\mathrm{Na}^{+}\right]\end{array}$ & $70 \cdot 48 \pm 0 \cdot 21$ & $0.53 \pm 0.21$ & $0 \cdot 41 \pm 0 \cdot 26$ \\
\hline
\end{tabular}

The units of $\mathrm{QO}_{2}$ are $\mathrm{ml} \mathrm{O}_{2}(100 \mathrm{~g} \text { min })^{-1}$.

* Indicates a value that is significantly different from each other number in that column $(P<0.05)$.

$\dagger$ Indicates a value that is significantly different from the darkadapted value in normal $\left[\mathrm{Na}^{+}\right]$.

were present, i.e. the photoreceptor cells. The average $\mathrm{QO}_{2}$ through the inner half of the retina was given by

or

$$
Q_{\mathrm{IR}}=Q_{3} \quad \text { if } L_{2}<\frac{L}{2}
$$

$$
Q_{\mathrm{IR}}=\left(Q_{2}\left(L_{2}-\frac{L}{2}\right)+Q_{3}\left(L-L_{2}\right)\right) \frac{1}{L / 2} \quad \text { if } L_{2}>\frac{L}{2}
$$

When both $Q_{2}$ and $Q_{3}$ were in the equation for $Q_{\mathrm{IR}}$, the $Q_{3}$ term usually dominated because $L_{2}-L / 2$ was small. The value of $Q_{\mathrm{IR}}$ was the rate of $\mathrm{O}_{2}$ consumption that would be measured if only the inner retina were present. This part of the retina corresponded to the inner nuclear, inner plexiform, ganglion cell, and nerve fiber layers.

Retinal $\mathrm{QO}_{2}$ values were calculated from parameters of the diffusion model and are listed in Table II. In dark and in normal $\left[\mathrm{Na}^{+}\right]$, the values of $Q_{\mathrm{OR}}$ and $Q_{\mathrm{IR}}$ suggest that the outer retina consumed $\mathrm{O}_{2}$ at $2 \cdot 2$ times the rate of the inner retina. In light and in normal $\left[\mathrm{Na}^{+}\right]$, the values of $Q_{\mathrm{OR}}$ and $Q_{\mathrm{IR}}$ suggested that the outer retina consumed $\mathrm{O}_{2}$ at 1.6 times the rate of the inner retina. In light, $Q_{\mathrm{OR}}$ was significantly less $(48 \%)$ than in the dark; a light-induced reduction of photoreceptor oxygen consumption was expected. In light, $Q_{\mathrm{IR}}$ was significantly less $(68 \%)$ than in the dark.

In the low $\left[\mathrm{Na}^{+}\right]$-low $\left[\mathrm{Ca}^{2+}\right]$ solution and in the dark, $Q_{\mathrm{OR}}$ was significantly less than the value for the dark-adapted retina in normal $\left[\mathrm{Na}^{+}\right]$, but not different from that in the light-adapted retina in normal $\left[\mathrm{Na}^{+}\right]$. On the other hand, $Q_{\mathrm{IR}}$ was not different from $Q_{\mathrm{IR}}$ in normal $\left[\mathrm{Na}^{+}\right]$. In low $\left[\mathrm{Na}^{+}\right]$, there was no lightinduced change in $Q_{\mathrm{IR}}$ or $Q_{\mathrm{OR}}$. However, there was some variability in the values of retinal $\mathrm{QO}_{2}$ measured in different retinas, due to the degree of trauma during dissection, or from variations between toads. A more sensitive way to examine the change due to light in the same retina was to calculate the paired difference in $\mathrm{QO}_{2}$. The values for the light-dark difference in the normal $\left[\mathrm{Na}^{+}\right]$condition were very similar to the results of the unpaired analysis of Table II. In low $\left[\mathrm{Na}^{+}\right]$, the light-induced change in retinal $\mathrm{QO}_{2}$ was evaluated in four tissues where the light-evoked $\mathrm{PO}_{2}$ response was at least $5 \mathrm{mmHg}$. There was a small, significant increase in $Q_{\text {entire }}, 0.03 \pm 0.02 \mathrm{ml} \mathrm{O}_{2}\left(100 \mathrm{~g} \mathrm{~min}^{-1}\right.$. that could not be detected from the unpaired values. The small increase in the $Q_{O R}$ value in light, $0.03 \pm 0.04 \mathrm{ml} \mathrm{O}_{2}(100 \mathrm{~g} \mathrm{~min})^{-1}$, was in the expected direction, based on $\mathrm{PO}_{2}$ responses to light (HaughScheidt et al., 1995), but was not statistically significant.

\section{Discussion}

\section{Retinal $\mathrm{PO}_{2}$ Profiles}

In the superfused toad retina, retinal $\mathrm{PO}_{2}$, regardless of condition of illumination or composition of the Ringer's solution, was highest at the innermost surface. Retinal $\mathrm{PO}_{2}$ decreased through the retina to a minimum in the outer retina and usually increased slightly near the RPE. This $\mathrm{PO}_{2}$ profile is not expected to be the same as the retinal $\mathrm{PO}_{2}$ profile in vivo, since $\mathrm{O}_{2}$ and nutrients in the intact retina would largely diffuse from blood vessels in the choroid. There are blood vessels on the vitreal surface of the retina (Wise, Dollery and Henkind, 1971), so presumably there is also some $\mathrm{O}_{2}$ supply from that side of the tissue in vivo. The altered delivery of $\mathrm{O}_{2}$ is not expected to affect retinal function or $\mathrm{QO}_{2}$. Tissue $\mathrm{PO}_{2}$ would also be lower in vivo. Evidence from cat retina shows that a modest degree of hyperoxia does not affect retinal $\mathrm{QO}_{2}$ (Linsenmeier and Yancey, 1989; Braun and Linsenmeier, 1995) whereas mild hypoxia could have affected $\mathrm{QO}_{2}$ (Linsenmeier and Braun, 1992).

It was difficult to judge the exact beginning (choroidal side) of the retinal profile. The transepithelial voltage was usually recorded across about $40 \mu \mathrm{m}$ as measured by the microelectrode pulling out of the tissue (Fig. 1), but RPE cells are only about $20 \mu \mathrm{m}$ wide. The distortion could have been due to the electrode tip sticking to the RPE cells as it moved through. Another possibility is that the electrode tip actually crossed the RPE at the beginning of the voltage change and the rest of the voltage increase occurred during sealing of the hole that the microelectrode had created in the RPE. For the analysis, the point halfway through the voltage change was judged as the beginning of the retinal profile. If the profile actually began earlier (see Fig. 1), in the calculation of $Q_{\text {entire }}, Q_{\mathrm{OR}}$ or $Q_{\mathrm{IR}}$, this would only affect the total retinal thickness value, $L$, and would mean that $\mathrm{QO}_{2}$ values reported are about $7 \%$ too large. An additional position error might have occurred from some movement of the tissue as a result of the electrode pushing or pulling on it. Although the length of the penetration was very similar to the length of the withdrawal, the retinal thickness determined from microelectrode withdrawal could be an overestimate due to uniform 


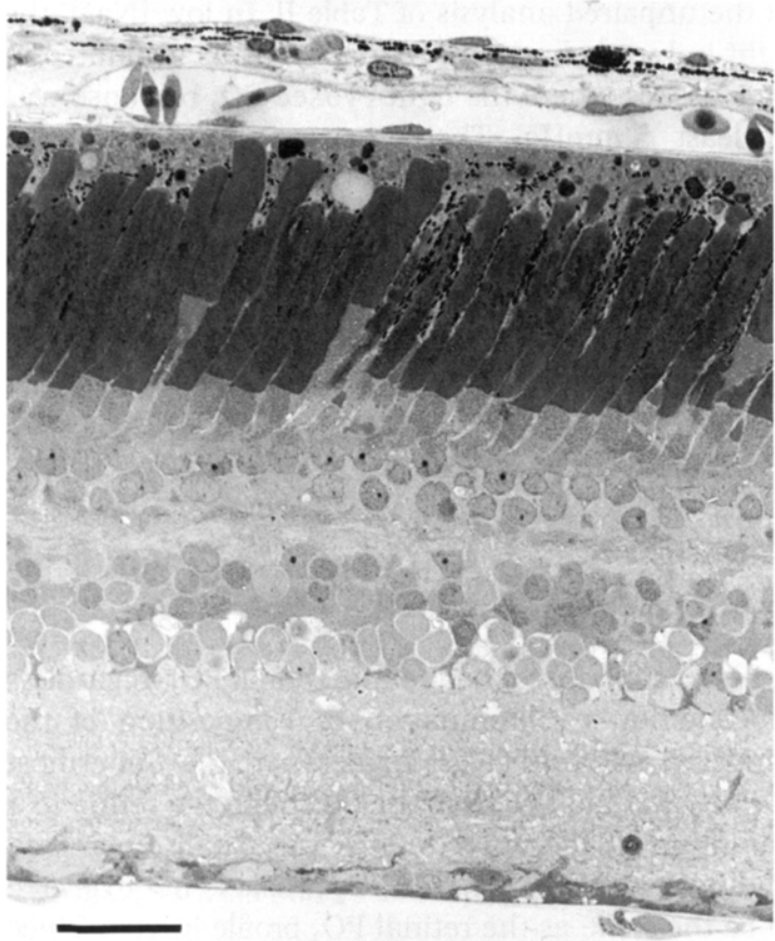

Fig. 5. A transverse section of the toad retina. The retina was fixed in a solution of $2 \%$ glutaraldehyde, then stained in a $50 / 50$ mixture of $1 \%$ toluidine blue and $1 \%$ sodium borate. The retinal section is oriented with the photoreceptor layer at the top. The scale bar indicates $50 \mu \mathrm{m}$.

stretching of the tissue by the electrode; thus the retinal $\mathrm{O}_{2}$ consumption values reported are possibly low.

\section{Retinal $\mathrm{PO}_{2}$ Diffusion Model}

The number and position of layers in the diffusion model were chosen strictly on the basis of fitting profiles and minimizing error, with no reference to the anatomy. These parameters can now be compared to the structure of the retina (Fig. 5). A 50- $\mu$ m-thick layer having negligible $\mathrm{O}_{2}$ consumption was found to be located adjacent to the RPE. This layer would contain only RPE cells and photoreceptor outer segments since rod outer segments of the toad are about $80 \mu \mathrm{m}$ long (Zhang and Straznicky, 1991) at the eccentricity where the profiles were measured. Results of the modelling indicated that there was no $\mathrm{QO}_{2}$ in this layer. RPE cells consume $\mathrm{O}_{2}$, but because they occupy a thin layer of the retina, and because of the uncertainty of the electrode positioning, their $\mathrm{QO}_{2}$ could not be detected with this method.

Layer 2 in the model (from $L_{1}$ to $L_{2}$ ) was about $100 \mu \mathrm{m}$ thick and corresponds to the proximal end of the outer segments, inner segments, outer nuclear layer, and outer plexiform layer (Fig. 5). Based on the anatomy, one would have expected layer 1 to be thicker and layer 2 to be thinner if the bulk of photoreceptor oxygen consumption occurs in the inner segments. This deviation was probably due to distortion in the profiles and/or an error in the choice for the beginning of the profiles. As noted in Methods, the position of the boundary between layers 1 and 2 is not determined with certainty, since somewhat larger values of $L_{1}$ and larger values of $Q_{2}$ would give almost the same error in fitting as did the optimum values. In either case, $Q_{O R}$ would be the same, and considerably more confidence can be placed in this value than in either $L_{1}$ or $Q_{2}$ alone. Interestingly, the model for the outer retina of toad required only two layers, while the one used previously for cat and monkey required three (Haugh et al., 1990; Ahmed et al., 1993). One difference between the species is that in mammals the part of the photoreceptor between the inner segments and the outer plexiform layer can be twice as long as the lengths of the inner and outer segment (Vogel. 1978). This layer had negligible $\mathrm{QO}_{2}$ in the cat retina (Haugh et al., 1990). The corresponding region is very thin in the toad (Fig. 5) and did not require a separate compartment in the modelling.

The third layer of the model for the toad corresponded almost exactly to the inner half of the retina, from the inner nuclear layer to the nerve fiber layer, a region in which modelling could not be applied to the normal cat retina. Recent work in cat has shown that a single layer is also adequate to describe $\mathrm{QO}_{2}$ in this part of the retina when the retinal circulation was occluded (Braun et al., 1995). Uniform oxygen consumption in the inner retina is undoubtedly an oversimplification for both retinas. Models with four and five layers were examined for the toad during development of the three-layer model reported here, but these models could not divide the inner retina consistently into different subcompartments, and generally did not yield a significant reduction in fitting error relative to the three-layer model (Haugh, 1992).

\section{Retinal $\mathrm{QO}_{2}$}

An objective of this study was to investigate the major components of retinal $\mathrm{QO}_{2}$ and estimate their magnitude under various conditions. It was expected that in a normal $\left[\mathrm{Na}^{+}\right]$solution, light would reduce $Q_{\text {entire }}$ and $Q_{\mathrm{OR}}$, and that $Q_{\mathrm{OR}}$ would probably be greater than $Q_{\mathrm{IR}}$; the results supported these hypotheses. The value of $\mathrm{QO}_{2}$ in the inner retina was always less than in the outer retina, $44 \%$ of $Q_{\mathrm{OR}}$ in darkness and $63 \%$ of $Q_{\mathrm{OR}}$ in light. A surprising result (not seen in the preliminary analysis (Haugh et al. 1992)), was that light reduced $Q_{\mathrm{IR}}$ as well as $Q_{\mathrm{OR}}$, although by a smaller amount. A light-evoked change in $Q_{\mathrm{I}}$ has not been observed in mammals (Bill and Sperber, 1990; Braun et al., 1995), nor, to our knowledge, been reported in any other species. It will be interesting to investigate the effect of flickering light, which would be expected to stimulate cells of the inner retina more than steady light, on $\mathrm{QO}_{2}$ of the inner retina. 
Removing $\mathrm{Na}^{+}$from the retina was expected to substantially reduce $\mathrm{Na}^{+} / \mathrm{K}^{+}$pumping by the photoreceptors, and therefore reduce $Q_{\mathrm{OR}}$. The effects of illumination as compared to inhibition of the $\mathrm{Na}^{+}$ pump were similar decreases in $\mathrm{QO}_{2}$, suggesting that essentially all the $\mathrm{Na}^{+}$pumping in the photoreceptors was light-dependent. This scheme is consistent with a large demand for $\mathrm{Na}^{+}$pumping by the photoreceptors in the dark. Under low $\left[\mathrm{Na}^{+}\right]$conditions, outer retinal $\mathrm{QO}_{2}$ was reduced by about $50 \%$, which is a somewhat smaller effect than that seen in the frog retina (Zuckerman and Weiter, 1980). The difference could have been due to an incomplete block of the photoreceptor $\mathrm{Na}^{+} / \mathrm{K}^{+}$pump, but adding ouabain during low $\left[\mathrm{Na}^{+}\right]$had no further effect on retinal $\mathrm{PO}_{2}$. In the inner retina low $\left[\mathrm{Na}^{+}\right]$did not reduce $\mathrm{QO}_{2}$ in the dark, suggesting that energetic processes other than $\mathrm{Na}^{+}$pumping must dominate $\mathrm{QO}_{2}$. The $\mathrm{QO}_{2}$ in the photoreceptor layer of the retina, in lowered $\left[\mathrm{Na}^{+}\right]$, was not significantly greater in light as compared to darkness. This result was surprising given the consistent light-evoked $\mathrm{PO}_{2}$ decrease in the lowered $\left[\mathrm{Na}^{+}\right]$condition (Haugh-Scheidt et al., 1995), which indicated a $\mathrm{QO}_{2}$ increase in the photoreceptors. The low $\left[\mathrm{Na}^{+}\right]$condition, maintained for as long as necessary to measure profiles in light and dark (about $2 \mathrm{hr}$ ), may not maintain the retina in a stable state. judged by the slow increase in retinal $\mathrm{PO}_{2}$ often observed in low $\left[\mathrm{Na}^{+}\right]$. A light-evoked increase in $Q_{\text {entire }}$ in low $\left[\mathrm{Na}^{+}\right]$was seen in the paired data.

Total oxygen utilization of the isolated toad retinaRPE in a dark-adapted state was $0.71 \mathrm{ml} \mathrm{O}_{2}(100 \mathrm{~g}$ min $)^{-1}$. This value is similar to the $\mathrm{QO}_{2}$ found in the frog retina in one study, $0.65 \mathrm{ml} \mathrm{O}_{2}\left(100 \mathrm{~g} \mathrm{~min}^{-1}\right.$ (reported as $10.6 \mathrm{nmol} \mathrm{O}_{2} \mathrm{~min}^{-1}$, Kimble et al., 1980) but about double that found in another study, $0 \cdot 26 \mathrm{ml}$ $\mathrm{O}_{2}\left(100 \mathrm{~g} \mathrm{~min}^{-1}\right.$ (Zuckerman and Weiter, 1980). Those studies measured $\mathrm{QO}_{2}$ by using an $\mathrm{O}_{2}$ balance within a closed chamber. The value of $\mathrm{QO}_{2}$ for the entire retina in this study decreased in light to $55 \%$ of the dark value, which was similar to the $43 \%$ decrease found in the frog retina (Zuckerman and Weiter, 1980 ) and the $60 \%$ decrease estimated from intracellular ADP levels in the toad retina (Apte, Ebrey and Dawson, 1993). Calculating $\mathrm{QO}_{2}$ from a $\mathrm{PO}_{2}$ profile and a diffusion model has the advantage of uncovering spatial heterogeneities in retinal $\mathrm{QO}_{2}$. From this technique, it was found that $Q_{\mathrm{OR}}$ for the toad retina in darkness was $1.0 \mathrm{ml} \mathrm{O}_{2}(100 \mathrm{~g} \mathrm{~min})^{-1}$ and during steady illumination it decreased to about $50 \%$ of the value in dark. In the dark-adapted cat retina, $Q_{\mathrm{OR}}$ (called $Q_{\mathrm{av}}$ there) was $4.4 \mathrm{mI} \mathrm{O}_{2}(100 \mathrm{~g} \mathrm{~min})^{-1}$, and decreased in light adaptation to $60 \%$ of the value in dark (Haugh et al., 1990). In other studies in the cat, $Q_{\mathrm{OR}}$ was $5 \cdot 1$ and $3.9 \mathrm{ml} \mathrm{O}(100 \mathrm{~g} \mathrm{~min})^{-1}$ in darkness, decreasing to $33 \%$ and $36 \%$ of those values respectively in light adaptation (Linsenmeier and Braun, 1992; Braun and Linsenmeier, 1995). Clearly the effect of light on $Q_{\mathrm{OR}}$ is similar in toad and in cat, and given the difference in temperature of the retinas, toad at $22^{\circ} \mathrm{C}$ and cat at $38^{\circ} \mathrm{C}$, it was expected that the toad retina would have a lower absolute $\mathrm{QO}_{2}$ than the cat retina. If one takes a value of $4.5 \mathrm{ml} \mathrm{O}$ ( $100 \mathrm{~g} \mathrm{~min})^{-1}$ for the cat, the ratio of $Q_{\mathrm{OR}}$ for the two species is 4.5. A value for the $Q_{10}$ of photoreceptor metabolism of 2.6 would predict this difference, although this may be partially coincidental, and factors besides temperature probably play at least some role in the difference in $Q_{O R}$ in the two species. The difference between $Q_{\mathrm{IR}}$ for the cat, $3.5 \mathrm{ml} \mathrm{O}_{2}$ $\left(100 \mathrm{~g} \mathrm{~min}^{-1}\right.$ (Braun et al., 1995), and the toad is larger, and would require a $Q_{10}$ of 3.6 to explain the difference solely on the basis of temperature. The lower metabolism in the toad is probably due to some combination of lower temperature, lower neuronal density, and possibly increased reliance of the nearly avascular inner retina of toad on glycolysis.

\section{Acknowledgements}

This study was supported by NIH grant EY05034 and the University of Cincinnati Research Council.

\section{References}

Ahmed, J., Braun, R. D., Dunn, Jr., R. and Linsenmeier, R. A. (1993). Oxygen distribution in the macaque retina. Invest. Ophthalmol. Vis. Sci. 34, 516-20.

Ames III, A., Ying-ying, L., Heher, E. C. and Kimble, C. R. (1992). Energy metabolism of rabbit retina as related to function: high cost of $\mathrm{Na}^{+}$transport. J. Neurosci. 12 . 840-53.

Apte, D. V., Ebrey, T. G. and Dawson, M. J. (1993). Decreased energy requirement of toad retina during light adaptation as demonstrated by ${ }^{31} \mathrm{P}$ nuclear magnetic resonance. J. Physiol. (Lond.) 464, 291-306.

Bill, A. and Sperber, G. O. (1990). Aspects of oxygen and glucose consumption in the retina: effects of high intraocular pressure and light. Graefe's Arch. Ophthalmol. 228, 124-7.

Braun, R. D. and Linsenmeier, R. A. (1995). Retinal oxygen tension and the electroretinogram during arterial occlusion in the cat. Invest. Ophthalmol. Vis. Sci., 36, 523-41.

Braun, R. D., Linsenmeier, R. A. and Goldstick, T. K. (1995). Oxygen consumption in the inner and outer retina of the cat. Invest. Ophthalmol. Vis. Sci., 36, 542-54.

Cohen, L. H. and Noell, W. K. (1965). Relationships between visual function and metabolism. In Biochemistry of the Retina (Ed. Graymore, C. N.). Pp. 36-49. Academic Press: New York.

Goldstein, D. A. (1979). Calculation of the concentrations of free cations and cation-ligand complexes in solutions containing multiple divalent cations and ligands. Biophys. I. 26. 235-42.

Goldstick, T. K. (1973). Oxygen Transport. In Engineering Principles in Physiology, Vol. II (Eds Brown, J. H. U. and Gann, D. S.). Pp. 257-82. Academic Press: New York.

Griff, E. R. (1990). Metabolic inhibitors reversibly alter the basal membrane potential of the Gecko retinal pigment epithelium. Exp. Eye Res. 50, 99-107.

Haugh, L. M. (1992). Oxygen consumption and light-evoked oxygen responses in the isolated toad retina. Northwestern University, Evanston, IL. Dissertation.

Haugh, L. M., Linsenmeier, R. A. and Goldstick, T. K. (1990). Mathematical models of the spatial distribution of 
retinal oxygen tension and consumption, including changes upon illumination. Ann. Biomed. Engr. 18, 19-36.

Haugh, L. M., Linsenmeier, R. A. and Griff, E. R. (1992). Oxygen consumption of the isolated toad retina during dark and light adaptation. Invest. Ophthalmol. Vis. Sci. 33 (Suppl.), 838.

Haugh-Scheidt, L. M. Griff, E. R. and Linsenmeier, R. A. (1995). Light-evoked oxygen responses in the isolated toad retina. Exp. Eye Res. 61, 73-81.

Kimble, E. A., Svoboda, R. A. and Ostroy, S. E. (1980). Oxygen consumption and ATP changes of the vertebrate photoreceptor. Exp. Eye Res. 31, 271-88.

Korenbrot, J. I. and Miller, D. L. (1989). Cytoplasmic free calcium concentration in dark-adapted retinal rod outer segments. Vision Res. 29, 939-48.

Linsenmeier, R. A. (1986). Effects of light and darkness on oxygen distribution and consumption in the cat retina. J. Gen. Physiol. 88, 521-42.

Linsenmeier, R. A. and Braun, R. D. (1992). Oxygen distribution and consumption in the cat retina during normoxia and hypoxemia. J. Gen. Physiol. 99, 177-97.

Linsenmeier, R. A. and Yancey, C. M. (1987). Improved fabrication of double-barreled recessed cathode oxygen microelectrodes. J. Appl. Physiol. 63, 2554-7.

Linsenmeier, R. A. and Yancey, C. M. (1989). Effects of hyperoxia on the oxygen distribution in the intact cat retina. Invest. Ophthalmol. Vis. Sci. 30, 612-18.

Medrano, C. J. and Fox, D. A. (1993). Light and pharmacologically induced decreases in rat photoreceptor and inner retinal respiration. Invest. Ophthalmol. Vis. Sci. 34 (Suppl.), 1279.

Miller, D. L. and Korenbrot, J. I. (1987). Kinetics of lightdependent $\mathrm{Ca}$ fluxes across the plasma membrane of rod outer segments: a dynamic model of the regulation of the cytoplasmic Ca concentration. J. Gen. Physiol. 90, $397-425$.

Miller, S. S. and Steinberg, R. H. (1977). Passive ionic properties of frog retinal pigment epithelium. J. Membr. Biol. 36, 337-72.

Press, W. H., Flannery, B. P., Teukolsky, S. A. and Vettering, W. T. (1989). Numerical Recipes: The Art of Scientific Computing. Cambridge University Press: New York, U.S.A.
Ratto, G. M., Payne, R., Owen, W. G. and Tsien, R. Y. (1988). The concentration of cytosolic free calcium in vertebrate rod outer segments measured with Fura- 2 . J. Neurosci. 8, 3240-6.

Robertis, E. D. (1956). Electron microscope observations on the submicroscopic organization of the retinal rods. J. Biophys. Biochem. Cytol. 2, 319-29.

Roh, H.-D., Goldstick, T. K. and Linsenmeier, R. A. (1990). Spatial variation of the local tissue oxygen diffusion coefficient measured in situ in the cat retina and cornea. Adv. Exp. Med. Biol. 277, 127-36.

Schneiderman, G. and Goldstick, T. K. (1978). Oxygen electrode design criteria and performance characteristics: recessed cathode. J. Appl. Physiol.: Respirat. Environ. Exercise Physiol. 45, 145-54.

Shimazaki, H. and Oakley. B. (1984). Decline of electrogenic $\mathrm{Na}^{+} / \mathrm{K}^{+}$pump activity in rod photoreceptors during maintained illumination. J. Gen. Physiol. 87, 633-47.

Sickel, W. (1972). Retinal metabolism in dark and light. In Physiology of Photoreceptor Organs. Handbook of Sensory Physiology, Vol. II/2 (Ed. Fuortes, M. G. F.) Pp. 667-727. Springer-Verlag: Berlin.

Sjostrand, F. S. (1953). The ultrastructure of the inner segments of the retinal rods of the guinea pig eye as revealed by electron microscopy. J. Cell. Comp. Physiol. 42, 45-70.

Stefansson, E., Wolbarsht, M. L. and Landers III, M. B. (1983). In vivo $\mathrm{O}_{2}$ consumption in rhesus monkey in light and dark. Exp. Eye Res. 37, 251-6.

Vogel, M. (1978). Postnatal Development of the Cat Retina. Springer-Verlag: Berlin.

Wise, G. N., Dollery, C. T. and Henkind, P. (1971). The Retinal Circulation. P. 68. Harper and Row: New York

Yau, K.-W. and Nakatani, K. (1984). Electrogenic Na-Ca exchange in retinal rod outer segment. Nature 311 , 661-3.

Yau, K.-W. and Nakatani, K. (1985). Light-induced reduction of cytoplasmic free calcium in retinal rod outer segment. Nature 313, 579-82.

Zhang, Y. and Straznicky, C. (1991). The morphology and distribution of photoreceptors in the retina of Bufo marinus. Anat. Embryol. 183, 97-104.

Zuckerman, R. and Weiter, J. J. (1980). Oxygen transport in the bullfrog retina. Exp. Eye Res. 30, 117-27. 